\title{
A Decisão Pericial no Âmbito da Previdência
} Social

\author{
MARIA DA PENHA PEREIRA DE MELO ${ }^{I}$ \\ ADA ÁVILA ASSUNÇÃO
}

A avaliação da capacidade laborativa dos segurados da Previdência Social que solicitam benefício por incapacidade, o auxílio-doença, é atribuição da Perícia Médica do Instituto Nacional do Seguro Social (INSS). Ter acesso ao benefício implica reconhecimento da existência de doença e de sua repercussão sobre a condição laborativa, na vigência de vínculo legal entre o segurado e a seguradora INSS. Este artigo apresenta resultados de pesquisa qualitativa desenvolvida com um grupo de treze médicos peritos. O trabalho desses peritos foi estudado utilizando-se categorias de análise da ergonomia e de técnicas de entrevistas e de autoconfrontação. O processo de decisão pericial foi estudado tomando-se como referência a noção de julgamento oriunda do Direito, tendo como marco teórico a Hermenêutica Jurídica, de Ronald Dworkin. Foram evidenciados conflitos na atividade médico-pericial, derivados da contraposição da demanda dos segurados com o ordenamento normativo da Previdência. Os resultados obtidos permitem afirmar que a avaliação pericial pressupõe a constituição de um código interpretativo constituído de princípios ordenadores de julgamento. Essa matriz interpretativa depende da forma peculiar de atuação e inserção social do profíssional. Sendo assim, a decisão (ou julgamento) não pode ser pensada independentemente das influências políticas de uma prática social.

Palavras-chave: Previdência social; perícia; interpretação; decisão; trabalho médico. 


\section{Introdução}

A Previdência Social integra, junto à área de Saúde e de Assistência Social, o que a Constituição de 1988 definiu como política de seguridade social. O Instituto Nacional do Seguro Social (INSS) é a autarquia do Ministério da Previdência Social responsável pela arrecadação das contribuições devidas à Previdência e pelo pagamento dos benefícios aos segurados. Entre os benefícios, encontram-se aqueles por incapacidade, sendo a Perícia Médica do INSS o corpo técnico responsável por emitir parecer conclusivo quanto à capacidade laborativa dos segurados, procedimento que produz efeitos de natureza médico-legal (Brasil, 1996).

Outras atribuições institucionais dos médicos peritos são: emitir parecer quanto à análise de tempo de serviço exposto a ambiente de trabalho insalubre, homologar exames periciais realizados por médicos de empresas conveniadas com o INSS e assessorar as Juntas de Recursos da Previdência Social e a Procuradoria do INSS.

Várias polêmicas em torno da atividade médico-pericial têm marcado os debates sobre a Previdência e gerado controvérsias sobre a estrutura, organização e formação dos profissionais do INSS (CUT Nacional, 2002; Verthein \& Gomes, 2001). Inúmeras críticas e queixas são destinadas aos resultados dos atos dos peritos da Previdência Social. Os sindicatos e os profissionais no campo da saúde do trabalhador acusam o corpo pericial de desrespeito aos segurados e de ausência de isenção, por atender de forma explícita aos interesses das empresas, negando a relação das queixas com o trabalho. A investigação em tela procura entender os componentes e as exigências das tarefas dos médicos peritos, para, em seguida, favorecer o debate social em torno da qualidade dos serviços prestados aos segurados. $\mathrm{O}$ objetivo do presente estudo é compreender as características do ato médico-pericial, notadamente quanto ao processo de decisão. Os resultados obtidos poderão fornecer subsídios que orientem a política institucional de formação dos médicos peritos. Ressalta-se, com fins de esclarecer o objeto das análises, que o grupo estudado dedica-se às avaliações de benefícios por incapacidade em geral e não, especialmente, àqueles destinados aos acidentes de trabalho.

Apesar da relevância social do trabalho desempenhado por esses profissionais, nota-se uma lacuna na compreensão do seu exercício. De um lado, conhecer, de forma mais sistemática, o trabalho dos peritos poderá contribuir para instrumentalizar investimentos institucionais em qualificação profissio- 
nal. Por outro, o trabalho dos peritos, enquanto expressão de uma política de governo, necessita de subsídios e espaços críticos para que se formulem ações voltadas para melhoria do atendimento ao segurado.

A hipótese orientadora da investigação foi elaborada a partir dos elementos reunidos em trabalho anterior, que permitiram compreender o ato médico-pericial como meio de operar o direito ao benefício por incapacidade (Melo, 2003). Nesse estudo, colocou-se em evidência elementos do raciocínio desenvolvido pelo médico perito na execução da tarefa de avaliação de incapacidade laborativa.

As características de imprecisão e variabilidade no material que compõe o processo de avaliação pericial impõem exigências ao profissional que não podem ser desconsideradas na formulação das políticas previdenciárias. Sendo imprecisos e variáveis, quais os caminhos adotados, que elementos os médicos peritos buscam e mobilizam para decidir? Seria pertinente entender a variabilidade nas decisões, fonte permanente de questionamentos dos resultados do ato pericial, como reflexo de atitudes típicas de um julgamento?

Para responder a essas perguntas, tentou-se avançar na compreensão do ato pericial, a fim de explicitar os caminhos até a decisão, tendo como referência a Filosofia do Direito e especialmente a abordagem da Hermenêutica Jurídica, de Ronald Dworkin ${ }^{3}$

Dworkin (1977) estabeleceu o conceito de princípio, que designa o padrão de justiça ou eqüidade, ou de alguma outra dimensão de moralidade, a ser seguido ou obedecido. Diante de um caso específico, os princípios podem ser conflitantes, divergentes, e o operador do direito pondera o peso de cada princípio envolvido naquela situação. Por isso, a decisão não é uma medida exata. Muitas vezes o julgamento poderá ser controverso entre operadores do direito, devido às distintas valorizações de princípios entre esses atores.

O mesmo autor formula ainda uma distinção entre princípio e regra. Para ele, as regras são equivalentes em importância e aplicáveis em um padrão de tudo ou nada. Ou seja, devem ou não devem ser aplicadas àquela situação e, quanto a isso, haveria um consenso universal. Dworkin prossegue defendendo que o orientador da decisão é o princípio e não a regra.

Mas se o caso a ser julgado é variável, impreciso e controverso, como garantir o direito? Entendendo o Direito enquanto um fenômeno social, Dworkin (1999a, 1999b, 2001a, 2001b, 2002) esclarece que o exercício da atividade judicante mobiliza proposições acerca do que a lei permite, proíbe ou autoriza. Os juízes utilizam-se de algo como uma teoria interpretativa da 
legislação, assim como os críticos literários possuem teorias para orientar sua análise das obras dos escritores. O juiz se municia de uma teoria ou teorias interpretativas fundadas em sua visão do Direito como um todo.

Reunindo conceitos filosóficos, sociológicos e literários, Dworkin sustenta que a prática jurídica depende fundamentalmente de uma teoria política, a qual implica um conjunto de elaborações desenvolvidas pelo operador do direito sobre a realidade de uma determinada época e uma dada sociedade. Dito de outra forma, num mesmo contexto, estilos diferentes de interpretação são fundados em diferentes teorias políticas.

A tese de Dworkin ajuda a entender o depoimento do médico perito, descrito adiante, segundo o qual a decisão nos casos de afecções músculoesqueléticas depende da posição que o médico assume diante da relação capital-trabalho. Para esse autor, a interpretação é construída a partir de releituras do conjunto normativo, que não independe dos princípios do intérprete. Sendo assim, a decisão dependeria de como o operador do direito, instrumentalizado por sua teoria jurídica, recolhe e valoriza os indícios trazidos pelo requerente do direito.

No seu exercício profissional, os operadores do direito podem discordar quanto à pertinência e ao peso de cada elemento (peça) do caso em julgamento. Isso se deve, em última análise, ao que cada operador entende por Direito, qual a sua abrangência e a quem se aplicaria. A interpretação depende da convicção, que é influenciada pelos paradigmas, pela experiência em julgamentos precedentes, e pelo próprio meio social. Dito de outro modo, a história e a prática moldam as interpretações.

Assim como cada médico não diagnostica segundo a sua cabeça, o juiz também não. $\mathrm{O}$ ato clínico, nas suas instâncias de observação, interrogatório e exame físico, converge para o ato de operar o direito. Tanto o raciocínio clínico quanto o raciocínio jurídico buscam recolher evidências baseadas em um método, uma interpretação e uma conclusão que dependem das injunções históricas e sociais, fenômeno denominado por Dworkin de convergência interpretativa. As técnicas da abordagem clínica convencional mobilizadas no ato médico-pericial (Melo, 2003) não conteriam elementos de convergência interpretativa para a decisão pericial? As decisões anteriores exaradas por outros peritos sobre o caso não contribuiriam para influenciar o julgamento atual? Os grupos sociais organizados não teriam peso na orientação das decisões?

Coerentemente com sua tese do Direito como prática interpretativa, Dworkin afirma, ao longo de sua obra, que existiria uma resposta correta 
para os casos controversos sob julgamento. A resposta correta, ou seja, a decisão, é específica, pois depende do operador e do caso, e será a melhor, diante daqueles elementos recolhidos e do conjunto normativo disponível.

Carvalho Netto (1999), a partir do registro da hermenêutica jurídica de Dworkin, entende o ordenamento jurídico como sendo composto dos resultantes da atividade interpretativa de todos os operadores do Direito. Com essa referência, o autor pondera que a qualidade operacional da norma dependerá das ações tomadas pelos intérpretes da norma. $\mathrm{O}$ operador do direito atuaria por meio de sua releitura do conjunto normativo à sua disposição, utilizando-se de forma subjacente ao seu exercício de julgamento, de princípios norteadores que, como regras gramaticais, condicionam a leitura do conjunto normativo. Prossegue destacando que, na análise do caso concreto, cabe ao juiz atentar para o todo normativo, considerando os fatos a serem julgados como "equivalentes a texto" (Carvalho Netto, 1999, pág. 483), ou seja, fatos que só na atitude interpretativa adquirirão sentido suficiente para que o julgamento resulte em uma decisão consistente, a melhor decisão. Esta se viabiliza pela unicidade de compromissos atualizados pelo julgamento do caso em análise.

A imparcialidade será possível unicamente pelo fato de o juiz considerar os fatos por todos os ângulos possíveis, trazendo a si, na análise do caso concreto, todo o ordenamento jurídico, enquanto pluralidade de normas que concorrem entre si, buscando, nesse julgamento, escolher qual norma trará mais justiça, considerando todos os elementos presentes no caso. Nessa visão, o ordenamento jurídico é tomado como um todo complexo, integrado por princípios contrários, concorrentes e, por isso mesmo, complementares entre si, ou seja, nunca contraditórios, muito embora excludentes, segundo a situação concreta de aplicação. Seria possível reconhecer na prática pericial tais procedimentos interpretativos, e especialmente, a ponderação de valores?

Magalhães (1999), ao analisar a interpretação no campo do direito, critica o positivismo aplicado ao direito. Segundo a autora, o positivismo, pressupondo regularidade, neutralidade e coerência conferida pelo edifício normativo, trata o direito como uma ciência normativa, em que o contexto e os usos são desconsiderados. Na visão positivista, a interpretação seria dita autêntica na medida em que fosse praticada pelos juízes, em um ato de vontade criadora, um exercício de poder discricionário. As normas jurídicas conteriam a característica de indeterminação e, dessa forma, estariam sujeitas à interpretação, sendo esta dependente da variabilidade da vontade do juiz, não haven- 
do, em última análise, decisão correta. Esta não seria a versão corrente na explicação quanto à atitude médico-pericial na condução de sua avaliação.

\section{Método}

A abordagem metodológica utilizada, de caráter qualitativo, priorizou a observação das situações reais de trabalho dos médicos peritos, usando conceitos e métodos propostos pela Ergonomia, explicitados em Lima (2000) e Assunção \& Lima (2003). Os autores, portando a noção de homem nãomaquinal, assumem uma visão de trabalhador enquanto agente de processos e mediações diante das demandas contextualizadas da produção, em que a variabilidade é a tônica, tanto do humano quanto do mundo produtivo.

Ao todo, treze médicos peritos participaram da pesquisa de campo. Dois médicos peritos convidados se recusaram a participar. Os participantes foram, em sua maioria, homens com idade média acima de cinqüenta anos e em torno de vinte anos de atividade como médicos peritos. Menos da metade possuía especialização em medicina do trabalho. Todos eram especialistas em outras áreas específicas da medicina e tinham outros vínculos empregatícios.

O trabalho de campo teve início com uma abordagem preliminar da instituição, incluindo pesquisa nos sistemas informatizados e divulgação da proposta de desenvolvimento da pesquisa junto a representantes da instituição.

Inicialmente, foram realizadas cinco entrevistas não-diretivas, totalizando cerca de dez horas de gravação. As entrevistas não-diretivas foram gravadas e transcritas, e aconteceram nos locais e horários de preferência dos entrevistados. O conteúdo das mesmas incluiu os históricos pessoais na instituição, a visão dos participantes sobre as transformações institucionais ocorridas na Perícia Médica ao longo do tempo, descrição e opiniões sobre o trabalho médico-pericial. A análise desses depoimentos contribuiu para eleger a tarefa de avaliação de incapacidade laborativa em consultório pericial como o núcleo da pesquisa. Além disso, constatou-se que essa tarefa, e somente ela, estava registrada nos "boletins de produção" dos sistemas informatizados institucionais.

Em seguida, foram realizadas sessões de observação do trabalho médicopericial, mais especificamente, da tarefa de avaliação da capacidade para o trabalho. Dez médicos peritos participaram dessa fase da pesquisa. Cada sessão de observação do trabalho durou em média noventa minutos. Durante 
as mesmas, foram feitos registros manuais dos eventos observados no transcurso do ato médico-pericial, ou seja, registraram-se as ações, procedimentos e diálogos ocorridos durante os atendimentos aos segurados pelo médico perito. Os registros, resultantes de cada sessão de observação do trabalho, depois de digitados, foram apresentados ao médico perito observado, buscando-se explicitação das motivações ou explicadores para o comportamento observado através de entrevistas de autoconfrontação. As entrevistas foram individuais, gravadas e tiveram duração, cada uma, de sessenta minutos.

As sessões de observação do trabalho e, em seguida, as entrevistas de autoconfrontação, ocorreram em consultórios de perícia médica, em sete Agências da Previdência Social pertencentes a três Gerências Executivas do INSS, na Região Sudeste do País, e aconteceram durante a jornada de trabalho do médico participante.

O conteúdo do material obtido das entrevistas não-diretivas, observações do trabalho e entrevistas de autoconfrontação foi analisado e categorizado segundo os temas evocado, sendo, em seguida, interpretado à luz das hipóteses construídas. Os procedimentos adotados obedeceram aos preceitos éticos recomendados em pesquisas envolvendo seres humanos. O consentimento informado foi obtido em contrato formalizado, após exposição dos propósitos da investigação e seus aspectos metodológicos, desfazendo-se possíveis temores sobre uma investigação preconceituosa ou de caráter punitivo. Esses aspectos não poderiam ser negligenciados, especialmente considerando-se a inserção da pesquisadora na instituição. Aos participantes, foi garantida confidencialidade.

\section{Resultados}

O médico perito, no extrato de entrevista de autoconfrontação abaixo reproduzida, define os elementos essenciais ao procedimento médico-pericial: exame clínico, exame documental, análise da atividade profissional exercida pelo segurado e enquadramento legal do caso em análise. Esses elementos são recolhidos "na parte documental que o segurado traz: do que ele está fazendo tratamento, se está tendo assistência, que exames ele apresenta", ou durante o exame clínico, e devem ser convincentes, ou seja, serem capazes de suscitar, no perito, a convicção quanto à incapacidade alegada pelo segurado. A este conjunto, o perito agrega, para fins de subsidiar sua decisão, o conhecimento da atividade de trabalho e o enquadramento legal 
da situação analisada. Todos esses aspectos são considerados na avaliação da capacidade laborativa do segurado. A análise do direito ao benefício por incapacidade é uma operação específica, individual para o segurado que está em avaliação naquele momento, como esclarece, abaixo, o médico perito:

"Eu vejo que a atividade médico-pericial é baseada no exame do segurado, na parte documental que o segurado traz: do que ele está fazendo tratamento, se está tendo assistência, que exames ele apresenta, que possam corroborar aquele estado dele. E o exame clínico, evidentemente, que pode ser de convencimento ou não, de que aquele segurado está incapaz. Aí entra a questão profissional, da atividade profissional do segurado, e o enquadramento legal. Você tem que entender de legislação, ver se aquele caso é pertinente em termos de vários aspectos da legislação que pode dar uma condição de direito ou não para aquele segurado receber aquele benefício" (MP 3).

O médico perito prossegue, buscando precisar o significado e a composição dessa convicção ou convencimento: "Convencimento não pelo que o segurado alega mas, sim, pelo que ele apresenta de objetivo" (MP 3). Aparentemente, o perito espera que o segurado demonstre, de forma inequívoca, sua condição de incapacidade, ou seja, apresente objetivamente comprovação que provoque nele, médico perito, convicção a respeito da condição alegada pelo segurado. Talvez essa fosse a situação ideal: o convencimento baseado em elementos positivos, factuais, quanto à existência da doença, associado ao enquadramento legal, embasando a conclusão pericial sobre a incapacidade.

Então, podemos afirmar que a decisão pericial diz respeito à existência ou não de doença, incapacitante ou não, face às exigências específicas da atividade profissional do segurado examinado, que pode resultar, ou não, no deferimento do benefício por incapacidade pleiteado, do ponto de vista da legislação vigente.

Observou-se, entre os médicos peritos estudados, que a decisão médicopericial é percebida como semelhante a um julgamento. Conforme o extrato de entrevista de autoconfrontação transcrito abaixo, o médico perito evoca a missão de juiz:

"Olha, eu não sei, a gente é meio juiz também, decide de certo modo sobre a vida do segurado, muitas vezes. Contra ou favorável, enfim, a gente tem uma certa alma de juiz, vamos chamar assim" (MP 4).

Em depoimento, uma perita reitera essa percepção da tarefa: "tem hora 
que a sensação que a gente tem é de julgamento mesmo". Explicita todo um conjunto de elementos que comporiam a situação de um julgamento: "todo mundo apresenta as provas, as provas verbais e as provas concretas escritas, daquilo que se está pleiteando".

Ao discriminar a forma de abordagem do responsável pela decisão, ela apresenta o ato pericial como caracteristicamente interpretativo: a conclusão ou julgamento se tornaria possível a partir da consideração ampla de todos os dados, em todos os ângulos possíveis na qual o perito "vai juntar tudo, vai ler tudo, vai olhar tudo, vai escutar todo mundo", para tornar possível "fazer um conceito final daquele caso, daquele processo e aquela pessoa determinada e vai dar o parecer final". Nesse movimento haveria, inevitavelmente, a participação do elemento pessoal, da interpretação. Essa interpretação possibilitaria a leitura desse material recolhido e the daria sentido, viabilizando a decisão.

No depoimento fica evidente, ainda, a existência da variabilidade na decisão pericial, dependendo do modelo interpretativo adotado pelo perito. Reconhece-se que "tem uma hora que essa decisão é pessoal. E tudo que é pessoal é passível de mais de uma interpretação" (MP 11).

A perita prossegue afirmando que essa visão da tarefa médico-pericial como assemelhada a um julgamento parece se acentuar "naquelas horas em que você não tem todos os elementos", ou seja, diante das situações nas quais a decisão tem que ser tomada sem uma convicção consolidada objetivamente. Esta certeza, "uma certeza do diagnóstico", nem sempre é possível. Imprecisão e incerteza que necessitam de superação tendo em vista a premência da decisão. Conviver com a dúvida tendo, mesmo assim, que decidir, parece ser parte do cotidiano desse profissional, no qual, a despeito da incerteza, o parecer deve ser exarado.

É pertinente lembrar que, legalmente, a avaliação médico-pericial produz efeitos administrativos tanto para o requerimento quanto para a manutenção de um benefício por incapacidade. Dessa forma, a conclusão pericial obrigatoriamente deve ser exarada pelo médico perito, ao fim do procedimento técnico de avaliação do segurado. O ingrediente da dúvida, segundo a perita, contribui para produzir sentimento de angústia em uma situação de trabalho fortemente determinada pela premência da decisão quanto ao atendimento, ou não, da reivindicação do segurado.

"Quando essas dúvidas chegam pra gente, às vezes elas chegam a ser angustiantes porque você tem um período de tempo relativamente curto, em que 
você tem que definir isso. Você está diante de uma pessoa que você tem que dar uma definição pra ela. Então, é angustiante por parte do médico, algumas vezes, que decisão você vai tomar quando a conjunção dos fatores todos ainda não te dá uma certeza do diagnóstico final” (MP 11).

Outra médica perita, na entrevista não-diretiva reproduzida a seguir, esclarece sua posição no caso de dúvida: "no caso de dúvida, a gente sempre favorece o segurado. Favorece no seguinte sentido: é o benefício da dúvida que você dá ao segurado" (MP 12).

Nesse exercício técnico essencialmente interpretativo, o juízo formado aparece orientado por princípios. A perita, no depoimento acima, afirma uma prática amparada em uma noção, o benefício da dúvida - in dubio pro misero - vinculada à intenção de não causar prejuízo. Segundo ela, nesses casos, ela tenderia a reconhecer a incapacidade, favorecendo o segurado. O objetivo desse procedimento seria evitar causar o prejuízo de negar benefício a alguém possivelmente incapaz. Considerou ainda que, nessas situações, em contrapartida, não se tem a certeza do contrário, ou seja, da existência de capacidade laborativa.

No depoimento a seguir, outra entrevistada também afirma a prática do benefício da dúvida e revela temor em causar dano ao direito do segurado. Ela considera ser freqüente, entre os peritos, a preocupação em não provocar prejuízo ao periciado:

"O sentimento maior é o medo de prejudicar. Quando você está realizando a perícia onde você não tem a certeza absoluta do diagnóstico e da condição de capacidade laborativa ou não, o medo maior de todo perito é (...) prejudicar o segurado" (MP 11).

À angústia mencionada pela profissional, diante da incerteza, junta-se o medo de causar prejuízo ao segurado, sentimentos intensos suscitados ambos no processo decisório. Esse valor, não causar dano, é também demonstrado no depoimento abaixo, oriundo de entrevista. Nele, o perito reconhece a prática do benefício da dúvida, qualificando a prática de liberal, e diferencia o benefício da dúvida do que considera ser seu oposto, a benevolência. Esse valor negativo, a benevolência, é reconhecido por esse perito, especialmente quando avalia a conduta de outros profissionais:

"Liberal, eu acho o seguinte, é o indivíduo que está doente, você tem dificuldade em estabelecer se há ou não incapacidade pra profissão dele e você dá o benefício, em dúvida pro réu. Mas quando você deliberadamente 
dá o benefício mesmo sabendo que o indivíduo não está incapaz, isso aí é diferente. Isso é ser benevolente" (MP 10).

É necessário esclarecer que, para os atendimentos periciais, os segurados são agendados, conforme disponibilidade do médico, segundo ordem de chegada na Agência da Previdência Social (APS). Ao solicitar um benefício por incapacidade e submeter-se à perícia, cada segurado passa a ter seu registro médico-pericial, personalizado, arquivado em um Envelope de Antecedentes Médicos (EAM) ou no sistema informatizado. De toda maneira, o perito, ao fazer o atendimento, tem acesso a todos os registros médicopericiais presentes no EAM do segurado, ou registrados no sistema informatizado. Essa visão geral é importante para a operacionalização da avaliação pericial, pois o segurado, enquanto for considerado incapaz, é reavaliado periodicamente.

Conforme pode ser evidenciado no recorte de entrevista de autoconfrontação reproduzido abaixo, o perito conceitua o valor negativo "benevolência" como sendo a concessão ou manutenção do benefício onde inexistem, ou melhor dizendo, onde não se encontram registros de elementos, provas "Exame inicial, o A x 1, sem nada" que possam justificar a concessão ou manutenção do benefício:

"São dois colegas mais benevolentes. Pegam um exame inicial, o A x 1, sem nada e, ao invés de conclusão negativa, $\mathrm{C}-1$, ou mesmo conclusão favorável mas com data de alta prevista, C-2, dão conclusão favorável sem previsão alta, C-4. E aí fica para mim e o Fulano fecharmos" (MP 7).

Existiria, então na função de perito, a intenção de não prejudicar o segurado. Entretanto, o perito não deve favorecer nenhum dos lados em sua decisão. A instituição previdenciária representaria o pólo da economia do recurso pecuniário e o segurado é o outro pólo, aquele que necessita da renda, sendo o perito o fiel dessa balança. No extrato de entrevista de autoconfrontação, abaixo reproduzido, a imparcialidade, exercida "de acordo com a técnica", mostra-se como ideal de uma prática de operação de direito na qual "ser justo" remete novamente ao papel de juiz:

"O compromisso do médico perito é trabalhar sem favorecer um lado nem outro, nem a instituição nem o segurado. Ser justo. Trabalhar de acordo com a técnica e ser justo" (MP 3).

O perito, na entrevista de confrontação abaixo, reafirma a utilização de princípios como a justiça. Para ele, na atividade médico-pericial, é necessá- 
rio ser justo e para isso deve-se "julgar como muito critério", ou seja, com um padrão definido que propicie uma apreciação dos fatos capaz de distinguir a verdade do erro: "Então, você tem que julgar aquilo com muito critério pra não ser injusto. Você pode ser injusto com uma pessoa com muita facilidade" (MP 7).

$\mathrm{Na}$ entrevista de autoconfrontação a seguir, o perito afirma ser justa a obediência às normas. A conclusão pericial não deve ser definida pela vontade do segurado, e sim pela obediência ao ordenamento normativo pertinente ao caso. O perito, enfatizando que "não posso dar o que não é meu", reafirma o compromisso de conceder o benefício caso constate existência de incapacidade, do contrário o benefício deverá ser negado. Aqui é evidenciada preocupação com a correção na decisão pericial, ou seja, a adequação entre a decisão e a existência de fatos justificadores da mesma:

"Eu tenho normas que devem ser seguidas. Se o segurado faz jus ao benefício na minha concepção, ele vai ter o benefício. Se ele não faz jus ao benefício, ele não terá o benefício. Eu não posso dar o que não é meu. Eu não vou dar o benefício porque a pessoa está querendo que dê o benefício. Se a pessoa estiver incapaz, ela vai ganhar o benefício, se ela não estiver incapaz, ela não vai ganhar. Essa é a regra. Eu não posso dar o que não é meu” (MP 6).

Aliada ao princípio da correção, a prática médico-pericial tem que mostrar idoneidade. Outro perito enfatiza a importância de registros do exame pericial conterem elementos descritivos e comprobatórios do exame do segurado que justifiquem a decisão, caracterizando dessa forma o que qualifica como idôneo na avaliação pericial:

"Mas idôneo é isso: você colher dados e documentações concernentes àqueles dados que comprovem aquilo que você escreveu. Dados que amparem a decisão dele. Que podem ser anexados nos arquivos" (MP 7).

Observou-se, durante sessão de acompanhamento da tarefa, um perito, por iniciativa própria, trocar com o colega, que ocupava consultório ao lado do seu, o envelope de antecedentes médico periciais de um segurado, ao verificar que havia feito as três últimas perícias daquele segurado. Ao ser indagado sobre o significado daquela atitude, afirmou inicialmente: "Eu vou trocar a perícia dele. Eu já fiz três exames com ele, com esse seria o quarto. Eu não acho isso certo" (MP 8).

$\mathrm{Na}$ entrevista de autoconfrontação, esse perito esclareceu que considera imprescindível a isenção na prática pericial. Segundo ele, a isenção ou au- 
sência de interesse em favorecer a demanda do segurado teria ainda que cumprir uma função exemplar "para os que estão do lado de fora". Ou seja, ele buscou demonstrar, com seu comportamento, que é isento e não se restringiu a somente concluir, a seu juízo, de forma imparcial:

"Em tudo na vida você tem que ser isento, e parecer para os que estão do lado de fora que se é isento. Por exemplo, fazer perícia de um amigo, mesmo que você seja isento, vai parecer para os que estão de fora que você está favorecendo" (MP 8).

Ao decidir sobre a capacidade para o trabalho, o médico perito define, na grande maioria das situações, o acesso a um benefício pecuniário, o auxílio-doença. Nesse julgamento, o tempo de contribuição do segurado para a Previdência versus a freqüência de requerimento de benefícios pelo segurado aparece como componente da análise médico-pericial. No depoimento abaixo, extraído de entrevista de autoconfrontação, o perito afirma que a relação entre tempo de contribuição e requerimento de benefícios compõe o "julgamento de valores" que ele utiliza em sua prática:

"Então esse julgamento de valores tem muito a ver com isso: o tempo que o sujeito tem de trabalho, o tempo que ele tem sem nenhuma reivindicação, qualquer requerimento. Porque tem gente que tem $n$ afastamentos em 3 ou 4 anos" (MP 7).

A expectativa do direito, segundo comenta outro perito, caracterizaria a demanda do segurado diante da avaliação pericial. Abaixo, ele relata que a percepção da intenção do segurado em receber o benefício é um dos determinantes de sua conduta durante a avaliação pericial: "O segurado chega com a expectativa de receber alguma coisa, entendeu? Ele não vem para tratamento, ele vem para receber um benefício. Ele já vem ansioso, nervoso" (MP 8).

Na prática pericial, o comportamento do segurado é analisado e, nessa análise, há uma conduta que procura uma possível exacerbação de sintomas ou sinais físicos ou mentais. O perito, em entrevista de autoconfrontação, distingue a atuação do segurado como honesta ou não, conforme seu comportamento durante a consulta pericial, afirmando: "O segurado honesto, às vezes ele anda normalzinho, você vai avaliar e ele está realmente incapaz" (MP 7).

A exacerbação ou valorização excessiva de sintomas, durante o exame clínico, aliada ao achado de sinais, "mãos cheias de calos", marcas corporais 
vistas pelo perito como demonstrações de desempenho de atividades incompatíveis com a pretensa incapacidade alegada pelo segurado, configuram, conforme entrevista de autoconfrontação reproduzida a seguir, quadro de simulação:

"O paciente procura sempre exacerbar aquilo que ele sente. Muitas vezes a gente examina um paciente que se queixa de dores nos braços e nas mãos em que não há condições nem de serem palpados, e muitas vezes notamos esses pacientes com as mãos cheias de calos. Então o paciente está simulando, e assim por diante" (MP 1).

A desconfiança aparece como elemento presente na prática médicopericial e é modulada, como será discutido adiante pela inserção do perito na sociedade e pelos seus valores. No extrato de entrevista de autoconfrontação abaixo, o perito relata elementos de sua vivência pericial que reforçam a desconfiança em relação ao segurado:

"Muitas vezes, já aconteceu comigo, o paciente chega no exame de perícia, todo se arrastando, todo claudicante, todo de muletas e, lá fora, esse paciente está tranqüilo, andando sem muletas, sem claudicação e bem. Então, realmente, é um setor de bastante desconfiança, muita desconfiança” (MP 2).

A desconfiança aparentemente se estende aos profissionais da área da saúde que, supostamente, compartilham a intenção do segurado em obter a concessão do benefício - por exemplo, os médicos dos serviços assistenciais. No depoimento abaixo, oriundo de entrevista não-diretiva, o médico perito relata sua experiência em relação aos atestados ou relatórios médicos emitidos pelos serviços assistenciais que buscam "forçar a gente a dar o benefício pra ele". Continua:

"Olha, assistência médica, eu, rapidamente posso colecionar pra você dezenas de atestados onde o sujeito fala assim: hipertensão de difícil controle, neurose depressiva de difícil controle, epilepsia de difícil controle. Então, todo o atestado que ele traz aqui é tentando forçar a gente a dar o benefício pra ele" (MP 5).

O perito, em seu julgamento da verdade, demonstra desconfiança também em relação ao pessoal administrativo da instituição, na medida em que pode ocorrer descumprimento de procedimentos de controle. Uma perita relata, em entrevista não-diretiva, que, em sua vivência institucional, já deparou com situações em que a concessão de benefícios sem limite definido 
ou aposentadoria por invalidez (benefícios sujeitos à confirmação de nível técnico de supervisão) é "concedido sem problema, sem ninguém barrar nada, e acontece. Simplesmente acontece. Porque alguém joga na máquina e pronto" (MP 13).

Essas percepções e registros oriundos da prática médico-pericial sinalizam o anteriormente mencionado, caráter de incerteza da tarefa. A busca da verdade leva o perito a adotar estratégias diante da suposição de simulação. Na entrevista não-diretiva reproduzida a seguir, a perita descreve "o macete" do exame físico utilizado para contornar a dificuldade derivada da hipótese de simulação:

Acreditar ou desconfiar do segurado é palco para o conflito do perito com as suas crenças e saberes, originando polêmicas sociais fortes sobre o papel da Previdência em geral, e o da medicina, em particular, na proteção da saúde e da vida.

O conhecimento da medicina, das doenças em seu desenvolvimento esperado com "coerência clinica, na evolução, na resposta terapêutica", é o subsídio para a conclusão quanto à veracidade ou não das queixas. No depoimento a seguir, a médica perita relata que confronta as queixas de distúrbios psíquicos dos segurados com a evolução conhecida dos distúrbios mentais. Ela também considera essa prática um macete:

"Porque todo caso em psiquiatria tem uma coerência clinica, na evolução, na resposta terapêutica, entendeu? Tem uns macetes pra se perguntar. A pessoa fala assim: 'ah, eu escuto vozes'. Isso todo mundo fala quando quer fingir que tá doido. 'Mas como são essas vozes'? E aí vem a coerência do quadro clínico. 'Essas vozes estão dentro ou fora da cabeça? Estas vozes te dão ordens?"” (MP 12).

Trabalhar de acordo com determinados valores na visão do perito, exposta na entrevista abaixo reproduzida, é percebido como algo individual, personalizado, dependente de uma formação de consciência, oriunda da educação baseada em preceitos. Em seu relato, a honestidade é ressaltada como valor a ser atualizado na prática pericial:

"Olha, eu acho que, a consciência, cada uma tem a sua. Meu pai era muito severo com os valores. Essa coisa de honestidade, esses preceitos. Ele era muito exigente com isso. Então, se eu fizer propositalmente uma coisa que eu acho que está errado, eu sofro com aquilo, aquilo me aborrece. Agora, acho que tem gente que não se incomoda muito com isso, vai dando um benefício 
(...). O pensamento às vezes, eu converso muito com os peritos, é que o País está cheio de corrupção e não adianta economizar com o segurado num benefício de R\$200,00 quando alguém está roubando milhões” (MP 10).

Em seu depoimento, fica exposto ainda um juízo crítico, pois, ao que lhe parece, "tem gente que não incomoda muito com isso, vai dando um benefício (...)". O relato alerta também para a existência de um discurso ("o País está cheio de corrupção e que não adianta economizar com o segurado num benefício de R\$200,00 quando alguém está roubando milhões") possivelmente originado na visão do benefício por incapacidade enquanto mecanismo de distribuição de renda.

Como o perito revela, diante da situação econômica precária da maioria dos que buscam o benefício por incapacidade, a prática médico-pericial é percebida, por seus atores, como uma oportunidade de realizar "justiça social":

"Esse beneficio aqui ele não é bom pras pessoas que têm boa renda. Primeiro, ele é limitado a cento e poucos reais. A grande massa dessa população aqui recebe um salário mínimo. E pra eles é de grande utilidade. Grande utilidade mesmo! Então, aí nós, médicos peritos, achamos que estamos fazendo um pouco de justiça social com eles" (MP 5).

Conforme depoimento obtido na entrevista não-diretiva reproduzida em seguida, a percepção do papel a ser desempenhado pela Perícia Médica vem passando por transformações, provavelmente repercutindo mudanças mais gerais na ordem política e social do País, que têm marco histórico no final da década de oitenta. A Perícia Médica passou de uma prática mais rigorosa, restritiva, para uma visão onde "o benefício foi feito pra ser dado e não negado" que se refletiria numa atitude distributiva:

"Isso aí foi mais ou menos, 1987. A Perícia começou, assim, talvez como eles falavam, a Perícia começou a ser uma distribuidora de renda, a ter um papel social, a atender melhor o segurado. O que na realidade, na minha opinião, a Perícia começou a conceder benefícios indevidos até, sabe. Falavase inclusive assim: que o benefício foi feito pra ser dado e não negado" (MP $10)$.

$\mathrm{Na}$ operação desse direito, o profissional muitas vezes protagoniza um conflito entre a extrema necessidade econômica, demonstrada pelo segurado, e a existência ou não do direito legal ao benefício. Em extrato de entrevista de autoconfrontação, um perito relata sua percepção de desgaste 
pessoal: "a gente vê uma pessoa profundamente necessitada mas não faz jus. Isso é terrível... Eu ainda sinto muito quando o sujeito precisa e não faz jus" (MP 7). Lidar com este tipo de situação parece ser, como descrito, fonte de angústia e insatisfação para esses profissionais. Em entrevista nãodiretiva, uma perita relata sentir-se insatisfeita diante do impasse gerado pela situação na qual a vontade de ajudar se confronta com "a coisa da maneira técnica", que deve ser obedecida:

“Cria uma insatisfação na gente, uma vontade de querer ajudar, mas na Perícia a gente não pode ser boazinha. A gente tem que fazer a coisa da maneira técnica, da maneira correta preenchendo as normas que nos são ditadas pra exercer. Essa pessoa é carente, ela precisa, mas ela não preenche os critérios. Como que eu vou passar por cima das normas, como que eu vou passar por cima do técnico? Eu vou escrever aqui que eu estou com dó da pessoa, que eu vou dar isso porque eu acho que ela merece?" (MP 13).

Outro depoimento sinaliza o conflito derivado de uma situação de trabalho onde se colocam objetivos contraditórios:

"Essa questão eu não consegui resolver, porque eu não sou agente de fazer justiça social, eu sou médico, médico é medico, é pra olhar doença. Ver se ele tem doença e se é incapacitante. Mas como é que eu fico livre desse troço. Gostaria dessa resposta. Como é que eu vou ficar livre disso?" (MP 5).

Os valores, positivos e negativos, os conflitos que se estabelecem e se atualizam ou se resolvem em estratégias várias, algumas mostradas aqui, o registro do contexto histórico e político, enfim, tudo isso, ou todos esses elementos, se encontram presentes no momento da decisão médico-pericial. No extrato de entrevista de autoconfrontação abaixo reproduzido, o perito enumera variáveis componentes da decisão, que apontam para a existência de uma teoria, composta do significado conferido, por ele, à sua atividade, e de sua visão a respeito do segurado, instruindo o processo decisório:

"E às vezes até, o próprio médico perito naquele momento, a visão dele da atividade que ele está exercendo, a visão dele do segurado que está na sua frente e (...) de tudo que envolve a situação de um modo geral, te faz ter uma conduta de raciocínio que pode levar você a um determinado resultado final, uma conclusão final" (MP 3).

Outro perito usa a expressão "inexplicável" ao comentar a interferência de seu ânimo pessoal no trabalho, influenciado por situações corriqueiras de 
seu cotidiano:

"É uma coisa inexplicável. Tem um dia que você tem um trajeto desde que você acorda até que chega aqui às 8 horas da manhã. Esse trajeto às vezes também influencia. Tem dia que você acorda meio atravessado, não é? E chega no trânsito tem um aborrecimento e até as influências do seu humor no dia. Até isso tem" (MP 5).

Todos os elementos presentes no cenário da avaliação, ou julgamento, parecem contribuir na formatação de uma matriz interpretativa, todos se amalgamando para conformar a decisão e, segundo diz uma perita, em entrevista não-diretiva, "se misturando naquilo ali, nesse ato pericial" e naquele sujeito, o médico perito. É fundamental, contudo, ressaltar que entender a atividade médico-pericial, enquanto prática interpretativa, significa realçar a diferença dos resultados dessa prática. Toda interpretação imprime uma direção aos elementos interpretados. Essa direção, reconhecida pelos peritos sob o nome de subjetividade, parece se tornar mais perceptível nas avaliações que envolvam doenças nas quais o diagnóstico não pode ser definido a partir de exames complementares, a exemplo das síndromes dolorosas relacionadas ao trabalho. Conforme afirma o perito no extrato de entrevista não-diretiva abaixo, o médico agiria subjetivamente, a partir de suas convicções políticas:

"O médico também fica sujeito à subjetividade e, mais ainda, ele fica sujeito a uma tendência política, da questão. Aí o médico age politicamente também. Se ele é a favor do segurado, ele acha que o segurado está doente, vitimado pelo trabalho. E, se ele é politicamente direitista, ele acha que o segurado é malandro que não agradece ao patrão de ter dado emprego pra ele e ter pago salário pra ele" (MP 5).

\section{Conclusão}

Ao se analisar a atividade médico-pericial, a partir da tarefa de avaliação da capacidade laborativa do segurado da Previdência Social, evidenciou-se a natureza interpretativa do trabalho do médico perito.

O código ou matriz interpretativa utilizado pelos médicos peritos é, em parte, constituído por elementos técnicos e normativos, tornados evidentes em outro artigo de tratamento de resultados dessa pesquisa (Melo, 2003) e por um conjunto de princípios. Esses princípios organizam a interpretação 
dos elementos trazidos ou recolhidos enquanto evidências justificadoras do requerimento de benefício por incapacidade. Os resultados apresentados permitem afirmar que esses princípios encontram-se aglutinados em torno da noção de justiça. Tornar evidente o caráter interpretativo da tarefa não é suficiente para explicar a conclusão ou julgamento pericial. É necessário indagar o que subjaz aos princípios, o que os reúne de uma forma peculiar, para aquele perito e não para o outro, produzindo julgamentos distintos.

Dworkin (2001) afirma que o juiz desenvolve uma teoria interpretativa para a abordagem do texto legal, a partir de sua convicção quanto à função do direito ou do sistema jurídico. Essa convicção é eminentemente derivada da forma peculiar de inserção do juiz na sociedade; em última análise, de seus conceitos políticos. Retomando Dworkin (2001, p. 32), "a interpretação no Direito é essencialmente política" e as convicções políticas dos juízes desempenham importante papel na escolha do estilo interpretativo.

Os resultados aqui apresentados ressaltaram aspectos como: a compreensão da instituição previdenciária e seu papel na diminuição dos efeitos das desigualdades econômico-sociais, o entendimento da dimensão e repercussões do trabalho médico-pericial no contexto dos benefícios por incapacidade, a visão de mundo do trabalho e seus determinantes. Esses aspectos, a nosso ver, constituiriam grandes cortes valorativos de dimensão política, organizadores de distintas teorias interpretativas vigentes entre os médicos peritos participantes da pesquisa.

O reconhecimento da existência da interpretação não deve ser confundido com a visão corrente, expressa inclusive em alguns registros empíricos da pesquisa, da necessária e admissível existência de espaços de discricionariedade, ou seja, de arbitramento, pelo operador, do direito diante de lacunas da lei. Concordamos com Dworkin (2001), quando ele afirma que, em função do caráter interpretativo da operação do direito, possam existir distintas avaliações sobre o mesmo conjunto de elementos em julgamento. Contudo, ele prossegue, o juiz, ao julgar, estabelece uma resposta correta desde que considere o caso em todos os ângulos possíveis e reúna a convicção necessária à sua decisão.

É necessário ressaltar que a medicina é também uma prática social e que, na atividade clínica habitual, ou nas diversas áreas especializadas médicas, compete ao profissional médico interpretar elementos, reações do corpo, fazer leituras e dar sentido dentro de sua prática e saber, configurando, assim, a realidade objetiva da doença, objeto de intervenção. Dessa forma, não podemos restringir o reconhecimento da interpretação aos casos 
polêmicos, duvidosos, ou às doenças não caracterizadas por componentes evidenciáveis pelos resultados de exames propedêuticos.

Enquanto prática social, a medicina reinventa, e mesmo cria a realidade do adoecimento, na medida em que nela se insere enquanto intérprete. Se pudermos afirmar, com Japiassu (1981), que o sujeito constrói o objeto de sua ciência, em relação ao perito é possível pensar que ele constrói o objeto de seu julgamento?

Por outro lado, o que ressaltamos, ao evidenciar a existência da matriz interpretativa enquanto constituinte do modus operandi do julgamento pericial, é a importância de reconhecer o caráter político, não neutro, dessa interpretação, ou seja, uma certa forma de ver ou reconhecer a realidade, que é uma construção social vigente naquele sujeito, o médico perito. Reconhecer essa dimensão aponta para a necessidade de problematizar os resultados dessa prática técnica e reavaliar o processo de trabalho médicopericial na instituição previdenciária.

Considerando a natureza da tarefa, é viável que a mesma seja realizada dentro do arcabouço institucional de um assessoramento técnico? O investimento institucional em formação e qualificação dos médicos peritos não deveria ter como foco as características do trabalho aqui destacadas? Os resultados apresentados sugerem repensar a inserção institucional desses profissionais, a fim de proporcionar uma modelagem de carreira técnica compatível com a natureza da tarefa.

A nosso ver, a exposição de conflitos derivados da oposição entre necessidade e direito evidenciados nos depoimentos dos peritos justifica maior ênfase institucional na delimitação, suporte e acompanhamento do papel técnico desses profissionais. Da mesma forma, acreditamos que a reação do segurado diante da decisão pericial possa ser um componente do processo de decisão, que mereça investigação específica.

Reconhecer o caráter interpretativo da atividade médico-pericial, entendida como uma prática de operação de direito, implica, conforme aponta Carvalho Netto (1999, p. 478), compreender o texto legal como "objeto da atividade interpretativa e não o seu sujeito". Desta forma, quaisquer mudanças, para serem efetivas, devem ocorrer no campo mesmo dessas práticas.

Esta pesquisa teve como objetivo estudar o exercício profissional do médico perito, de forma a ajudar a compreender o ato médico-pericial e, dessa forma, contribuir para o aprimoramento de um exercício profissional. As características peculiares da atividade médico-pericial, aqui apontadas, podem ser entendidas como insumos para a formulação e desenvolvimento 
de uma política institucional de qualificação. Enquanto investigação, não pretendeu descrever todos os componentes do trabalho, mas estabelecer um ponto de análise do mesmo. Vários aspectos do trabalho médico-pericial restaram por abordar, ou necessitam de abordagem mais refinada: por exemplo, a relação médico perito-segurado.

Finalmente, é pertinente salientar que a forma e o alcance das políticas sociais, em uma sociedade democrática, necessitam ser permanentemente revistos pelo conjunto dessa sociedade, através de suas instâncias representativas, como os Conselhos de Seguridade Social, e não somente pelas instâncias institucionais.

\section{Referências Bibliográficas}

ASSUNÇÃO, A. A.; LIMA, F. P. A. A nocividade do trabalho: contribuição da ergonomia para a identificação, redução e eliminação da nocividade do trabalho. In: MENDES, R. (Org.) Patologia do trabalho. 2. ed. São Paulo: Atheneu, 2003. p.1.767-1.789.

BRASIL. Consolidação dos atos normativos sobre serviços previdenciários. Brasília: Ministério da Previdência Social, 1996. v.1, parte 1. (documento de circulação interna).

CARVALHO NETTO, M. Requisitos pragmáticos da interpretação jurídica sob o paradigma do Estado Democrático de Direito. Revista de Direito Comparado, Belo Horizonte, v.3, p.473-486, 1999.

CENTRAL ÚNICA DOS TRABALHADORES. Conclusões do Seminário Nacional: presente e futuro da Previdência Social Pública no Brasil e na América Latina. In: . PROPOSTAS da CUT para a Previdência

Social Pública: diretrizes e ações da CUT para atuação junto aos conselhos de Previdência Social. São Paulo: CUT Nacional, 2002, p. 139-144.

DWORKIN, R. Is the law a system of rules? In: (Ed.). The philosophy of law. Oxford Readings in Philosophy. New York: Oxford University Press, 1977. p. 38-65.

DWORKIN, R. O que é o direito? In: O império do direito. São Paulo: Martins Fontes, 1999a. p.3-54.

DWORKIN, R. Conceitos de interpretação. In: reito. São Paulo: Martins Fontes, 1999b. p.55-108.

DWORKIN, R. O fundamento político do direito. In: O império do di.Uma questão 
de princípios. São Paulo: Martins Fontes, 2001a. p.3-171.

DWORKIN, R. O direito como interpretação. In:

. Uma questão de princípios. São Paulo: Martins Fontes, 2001b. p.175-276.

DWORKIN, R. Casos difíceis. In: . Levando os direitos a sério.

São Paulo: Martins Fontes, 2002. p.127-203.

LIMA, F. P. A. A formação em ergonomia: reflexões sobre algumas experiências de ensino da metodologia de análise ergonômica do trabalho. In: FAGÁ, I.; IESER, C.; SAMPAIO, M. R. (Coord.). Trabalho, educação e saúde: um mosaico em múltiplos tons. São Paulo: Fundacentro, 2000. p.133148.

JAPIASSU, H. Objetividade científica e pressupostos axiológicos. In: O mito da neutralidade cientifica. Rio de Janeiro: Atheneu, 1981. p.55-81. MAGAlHÃES, J. N. Sobre a interpretação jurídica. Revista de Direito Comparada, Belo Horizonte, v. 3, p. 429-450, 1999.

MELO, M. P. P. Condições do exercício profissional do médico perito da Previdência Social. Dissertação (Mestrado em Saúde Pública) - Programa de Pós-Graduação em Saúde Pública, Faculdade de Medicina da Universidade Federal de Minas Gerais. Belo Horizonte, 2003.

VERTHEIN, M. A. R.; GOMES, C. M. As armadilhas: bases discursivas da neuropsiquiatrização das LER. Ciência e Saúde Coletiva, Rio de Janeiro, v.6, n. 2., p.457-470, 2001.

\section{NOTAS}

1 Mestranda em Saúde Pública, na área de concentração Saúde e Trabalho, Universidade Federal de Minas Gerais. Chefe do Serviço de Gerenciamento de Benefícios por Incapacidade da Gerência Executiva do INSS em Belo Horizonte (MG).

2 Professora orientadora do Programa de Pós-graduação em Saúde Pública da Faculdade de Medicina da UFMG. Doutora em Ergonomia pelo Laboratório de Ergonomia Fisiológica e Cognitiva, na EPHE, Paris.

3 Estudioso norte-americano de Filosofia do Direito. 


\section{ABSTRACT}

Forensic Medical Reports in the Brazilian Social Security System

Evaluation of the work capacity of individuals covered by the Brazilian Social Security System who file for disability benefits and sick leave is the responsibility of the Forensic Medicine Division of the National Institute of Social Security (INSS). Claiming such benefits requires proving the existence of the disease or injury and its repercussions on the individual's capacity to work, in the presence of the individual's coverage by the INSS. This article presents the results of a qualitative survey of a group of 13 physicianreviewers. Their work was studied using ergonomic analytical categories and interviews and self-confrontation techniques. The physician-reviewer decisionmaking process was studied based on the notion of judgment from the field of Law, with Ronald Dworkin's Legal Hermeneutics as the theoretical framework. Conflicts were found in physician-reviewer activity, resulting from the opposition between the demands by claimants and the normative ordering of the Social Security System. According to the results, physician review presupposes the establishment of an interpretative code consisting of underlying judgmental principles. This interpretative matrix depends uniquely on the physician-reviewer's activity and social insertion. Thus, the decision or review cannot be conceived independently of the political influences of a social practice.

Keywords: Social Security; forensic medical reports; interpretation; decision; medical work.

Recebido em: 12/05/2003.

Aprovado em: 05/09/2003. 